\title{
Telangiectatic adenoma - computed tomography and magnetic resonance findings: a case report and review of the literature
}

\author{
Tatiana Chinem Takayassu1, Edson Marchiori*1,2, Antonio Eiras ${ }^{1,3}$, \\ Rafael Ferracini Cabral ${ }^{1}$, Fernanda Caseira Cabral ${ }^{1}$, Raquel Ribeiro Batista ${ }^{1}$, \\ Gláucia Zanetti ${ }^{1}$ and Paula Cristina Pereira Dias ${ }^{1}$
} \begin{abstract}
CEP 21941-913, Brazil, 2Department of Radiology of the Fluminense Federal University. Rua Marquês do Paraná, 530. Centro. CEP 24000-000 CEP 22775-002, Barra da Tijuca. Rio de Janeiro, Brazil

Email: Tatiana Chinem Takayassu - tatianachinem@yahoo.com.br; Edson Marchiori* - edmarchiori@gmail.com; Antonio Eiras - antonioeiras@globo.com; Rafael Ferracini Cabral - rafaferrac@yahoo.com.br; Fernanda Caseira Cabral - fecabral4@hotmail.com; Raquel Ribeiro Batista - raquelr.batista@ig.com.br; Gláucia Zanetti - glauciazanetti@gmail.com; Paula Cristina Pereira Dias - pcpdias@gmail.com

* Corresponding author
\end{abstract}

Address: ${ }^{1}$ Department of Radiology of the Federal University of Rio de Janeiro. Rua Professor Rodolpho Paulo Rocco, 255. Cidade Universitária. Niterói. Rio de Janeiro. Brazil and ${ }^{3}$ Department of Radiology, Hospital Barra D'Or, LABS-D'Or Hospital Network, Avenida Ayrton Senna, 2541.

Published: 7 January 2009

Cases Journal 2009, 2:24 doi:10.1186/1757-1626-2-24

This article is available from: http://www.casesjournal.com/content/2/I/24

(C) 2009 Takayassu et al; licensee BioMed Central Ltd.

This is an Open Access article distributed under the terms of the Creative Commons Attribution License (http://creativecommons.org/licenses/by/2.0), which permits unrestricted use, distribution, and reproduction in any medium, provided the original work is properly cited.
Received: 2 January 2009

Accepted: 7 January 2009

\begin{abstract}
Telangiectatic adenoma is a new classification of a hepatic lesion. It was previously named telangiectatic focal nodular hyperplasia but it is in fact true adenoma with telangiectatic features. We report here a case of telangiectatic adenoma in a 72-year-old woman. The image features are lack of a central scar, a heterogeneous lesion, hyperintensity in TI-weighted MR images, strong hyperintensity in T2-weighted MR images, and persistent contrast enhancement in delayed-phase contrast-enhanced CT or TI-weighted MR images. It is a monoclonal lesion with potential of malignancy. The treatment of telangiectatic adenoma is surgery, the same way as hepatic adenoma. Focal nodular hyperplasia may be managed by clinical follow-up alone.
\end{abstract}

\section{Background}

Telangiectatic adenoma (TA), previously known as telangiectatic focal nodular hyperplasia, was recently redefined as a variant of hepatocellular adenoma (HA), based on molecular and genetic evidence. This redefinition has potential clinical relevance because telangiectatic adenomas must be as aggressively managed as hepatocellular adenomas. Here we describe a case of a female patient presenting with a liver mass which turned out to be TA, and discuss this new pathological entity and its differential diagnosis, with emphasis on interpretation of imaging results.

\section{Case presentation}

A 72-year-old asymptomatic woman presented to the clinic for a checkup. She had a history of cholecystectomy, hypothyroidism, and hypertension. She had been treated with thyroid hormone (Puran $\left.{ }^{\circledast} \mathrm{T} 4,75 \mu \mathrm{g}\right)$, an anti-hypertensive agent (the angiotensin-converting enzyme inhibitor Enalapril ${ }^{\circledast}, 20 \mathrm{mg}$ ), an antiarrhythmic drug (Diltiazem $\left.{ }^{\oplus}, 90 \mathrm{mg}\right)$, and acetylsalicylic acid $(200 \mathrm{mg})$. She reported use of oral contraceptives for over 30 years. She had no history of smoking, drinking, drug abuse or family history of liver disease. 
On physical examination, the liver was palpable to $6.5 \mathrm{~cm}$ from the right costal, and $10 \mathrm{~cm}$ from the appendix xiphoid; it was painless, and had a rugged and hard consistency. Laboratory studies revealed the following: red

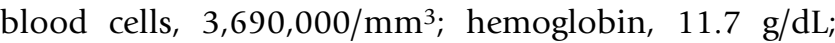
hematocrit, 35\%; platelets, $278,000 / \mathrm{mm}^{3}$; cholesterol, $186 \mathrm{mg} / \mathrm{dL}$; triglycerides, $70 \mathrm{mg} / \mathrm{dL}$; glucose, $85 \mathrm{mg} / \mathrm{dL}$; TSH, $2.8 \mathrm{U} / \mathrm{mL}$; serum creatinine, $0.7 \mathrm{mg} / \mathrm{dL}$; ALT, $47 \mathrm{U} /$ L; AST, $29 \mathrm{U} / \mathrm{L} ; \mathrm{GGT}, 23 \mathrm{U} / \mathrm{L}$; alkaline phosphatase, 138 $\mathrm{U} / \mathrm{L} ; \mathrm{TB}, 0.8 \mathrm{mg} / \mathrm{dL} ; \mathrm{DB}, 0.4 \mathrm{mg} / \mathrm{dL} ; \mathrm{PT}, 12 \mathrm{~s} ; \mathrm{INR}, 1.0$; PTT, 29 s; folic acid, $11 \mathrm{mg} / \mathrm{mL}$; alpha-fetoprotein, 2.08 $\mathrm{ng} / \mathrm{mL}$; iron, $106 \mu \mathrm{g} / \mathrm{dL}$; vitamin B12, $210 \mathrm{pg} / \mathrm{mL}$; ferritin, $170 \mathrm{mg} / \mathrm{L} ; \mathrm{LDH}, 384 \mathrm{IU} / \mathrm{L}$; and CEA $2.4 \mathrm{ng} / \mathrm{mL}$.

Abdominal ultrasound revealed an enlarged and heterogeneous liver that contained an expansive and heterogeneous lesion measuring $14 \times 9.4 \mathrm{~cm}$ with poorly defined limits, including two echogenic nodular areas, measuring 6.3 and $3.2 \mathrm{~cm}$, respectively. The gallbladder was not visualized.

Computed tomography (CT) of the upper abdomen (Figure 1) showed a heterogeneous lesion - measuring $15 \times$ $14 \times 10 \mathrm{~cm}$ - with a partially well-defined margin and hypodense permeating areas, some with attenuation values compatible with soft parts, and others with liquefaction located in the left liver lobe. After endovenous contrast injection, the lesion showed intense and non-

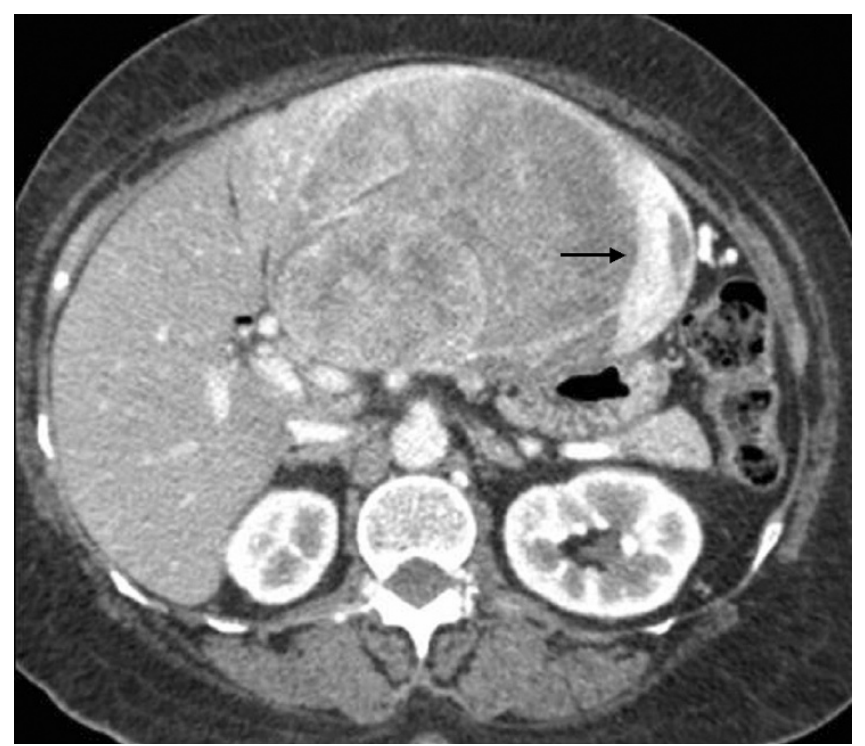

Figure I

Portal-stage contrast-enhanced helical CT of the upper abdomen. Impregnation by the contrast agent shows a large, solid, exofitic lesion compromising the left liver lobe. The enhancement is intense and heterogeneous, the dominant portion being in the periphery of the lesion (arrow). homogeneous impregnation in the arterial and portal phases, with hypodense permeated areas located in the left lobe, notably parts II and III; these areas determined recoil and reduced the size of vascular structures adjacent to the liver. The injury also caused bulging of the border of adjacent liver tissue, causing a compressive effect on other abdominal structures, especially the stomach and pancreas.

Magnetic resonance (MR) imaging of the upper abdomen showed different components within the lesion. T2weighted images in the peripheral region showed a discrete heterogeneous hyperintense signal, while the central portion was hypointense. In T1-weighted images, the signal in the periphery of the mass was similar to the muscle signal and the center of the lesion showed a signal that was clearly hypointense. Although impregnation of both components began in the arterial phase, the peripheral region showed a stronger signal during the arterial and portal phases, followed by signal decay in the late phase due to relatively rapid washout, indicative of hypervascularization. The center of the mass was far more intense in the late phase, probably due to slow flow through the vascular components (Figures 2 and 3 ).

Surgery and pathological analysis revealed a hepatic segment measuring $17.5 \times 14 \times 8 \mathrm{~cm}$ and weighing $1200 \mathrm{~g}$ that contained a $15 \times 9 \mathrm{~cm}$ brown tumor with ill-defined limits. The tumor had a gelatinous component and showed hemorrhaged, necrotic, and cystic areas. The final

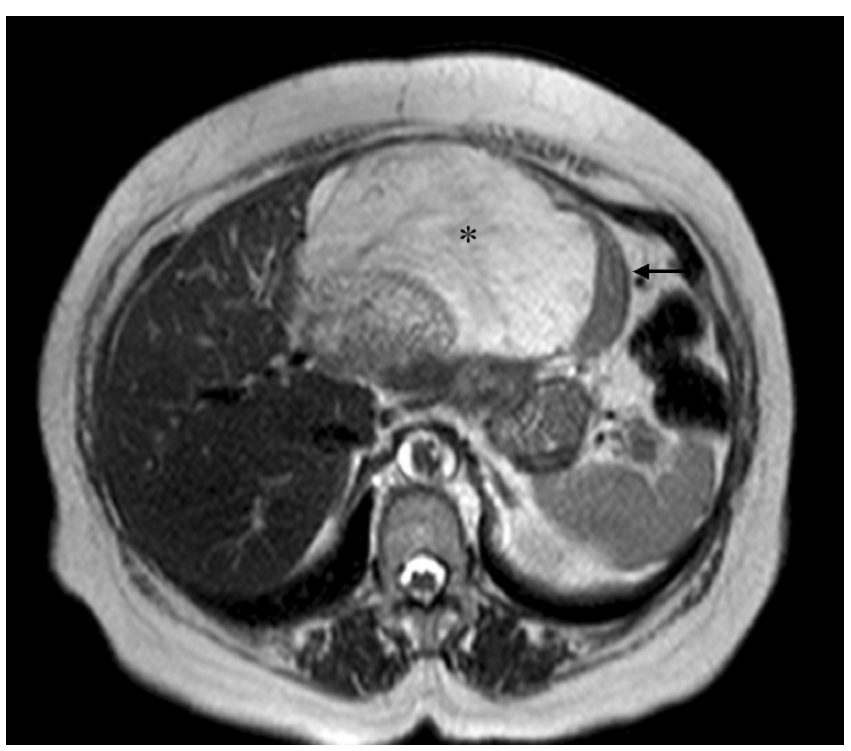

Figure 2

MR imaging sequence with T2-weighted transversal. Imaging shows a hypointense signal originating in the peripheral region (arrow) and a dominant component associated with a hyperintense signal $(*)$. 


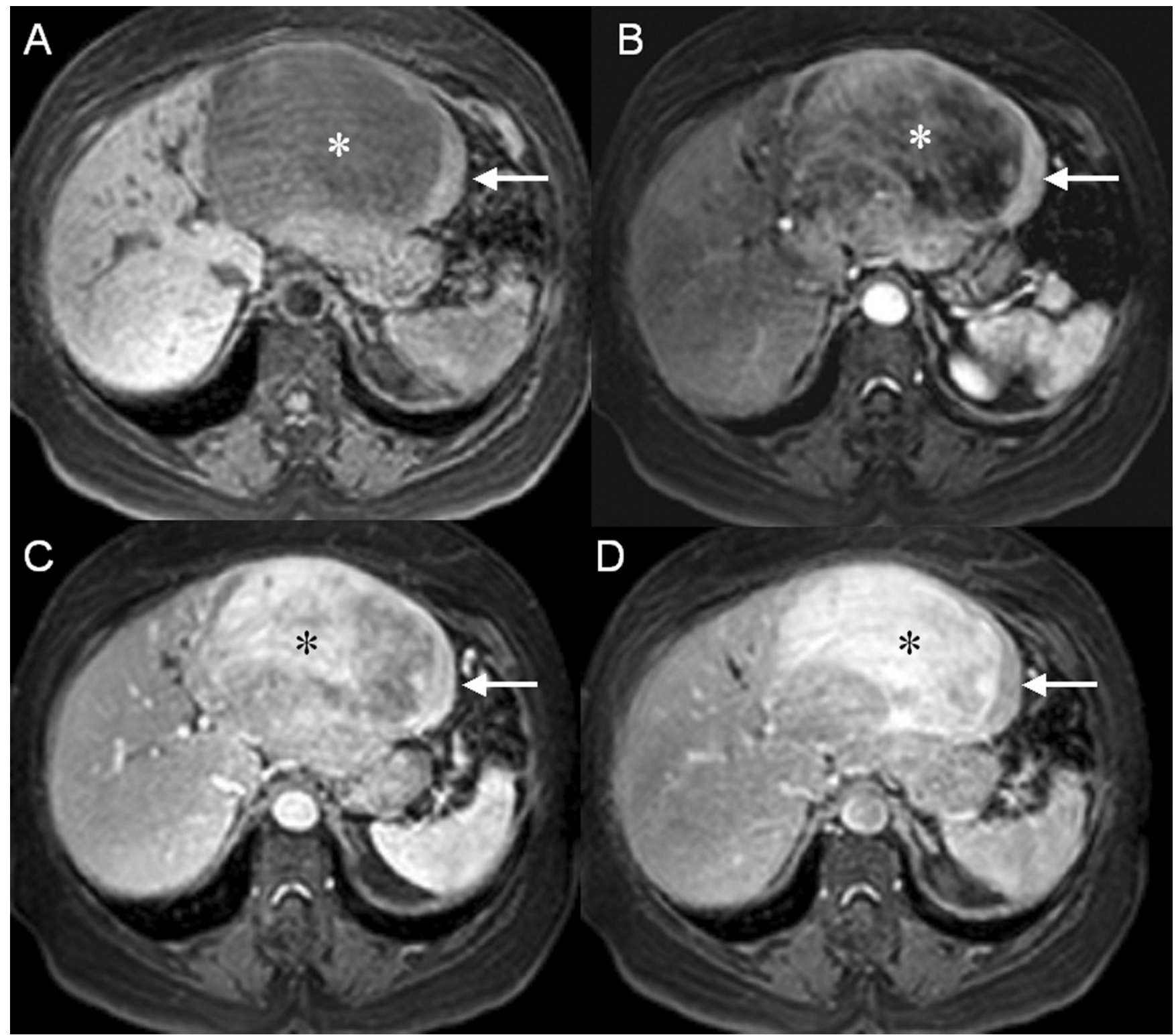

\section{Figure 3}

(A) T I-weighted fat-suppressed MR imaging without contrast; and MR imaging after contrast in (B) arterial phase, (C) portal phase, and (D) late phase. In TI-weighted images without contrast, the signal in the periphery of the mass (arrow) is similar to the muscle signal; the center of the lesion clearly shows a hypointense signal (*). Although impregnation of both components began in the arterial phase, the peripheral region (arrow) showed a stronger signal during the arterial and portal phases, followed by signal decay in the late phase due to relatively rapid washout, indicative of hypervascularization. The enhancement of the central component is far more intense in the late phase $\left(^{*}\right)$, probably due to a large interstitial space and slow flow through the vascular components.

diagnosis was TA. The patient progressed well and she remains asymptomatic after one year of follow up.

\section{Discussion}

Focal nodular hyperplasia (FNH) and liver cell adenoma (LCA) are the most frequent benign epithelial lesions of the liver observed in young female patients using oral con- traceptives. Although they are both benign, the management of these two types of lesions is radically different, consisting of clinical follow-up for FNH and surgical resection for liver cell adenoma [1,2].

FNH is the second most common benign liver tumor, occurring predominantly in young and middle-aged 
women $[3,4]$. The tumor-like lesions probably result from a hyperplastic liver response to a focal blood flow increase related to pre-existing arterial malformation [4,5]. Their polyclonal nature suggests that they are part of a regenerative process; consequently, they are unlikely to present a risk of malignancy [1].

FNH is usually asymptomatic and is often discovered fortuitously. A non-operative approach has been adopted by most hepatobiliary centers because there are no proven cases of malignant degeneration. Pain may sometimes be present, particularly in the case of a large tumor, but hemorrhage is very rarely reported [6]. Unlike adenomas, 70\% of cases of FNH may be diagnosed by imaging techniques alone [2]. The recommended follow-up consists of serial ultrasonography. The main goal of imaging in $\mathrm{FNH}$ patients is to firmly establish the diagnosis in order to avoid surgical resection and to confirm that a conservative approach to therapy is appropriate $[7,8]$.

LCA is a rare hepatic tumor that is characterized pathologically by the benign proliferation of hepatocytes [4]. These tumors are strongly associated with oral contraceptive use [9]. Distinction between LCA and FNH is not possible based only on clinical and laboratory data.

LCA usually comprises a single nodule; more rarely, multiple nodules may be present $[10,11]$. In contrast to regenerative lesions such as typical FNHs, LCAs are monoclonal tumors, suggesting that they display neoplastic rather than regenerative behavior; consequently, they may present a risk of malignancy [1]. LCAs are usually symptomatic, presenting with abdominal pain or abnormal liver function tests. Surgical resection is advocated based on the high incidence of bleeding complications and reports of neoplastic degeneration [8]. Because of these risks of spontaneous rupture and malignant transformation, LCAs must be identified and treated promptly.

Based on previous studies, it is now clear that the lesions previously named telangiectatic focal nodular hyperplasias are in fact true adenomas with telangiectatic features; hence they are now referred to as telangiectatic adenomas (TAs). This new classification is based on both morphological and molecular features, and takes into consideration the results of clonal analysis and gene expression studies. It should be emphasized that the new classification has clinical relevance; aggressive management of these cases should be considered. However, it remains to be established whether the clinical behavior of TAs, including the associated risk of malignant progression, resembles that of LCA more than $\mathrm{FNH}$.

TA is defined as a benign well-differentiated proliferation of hepatocytes in which vascular changes, including tel- angiectatic features, are prominent [9]. Clonal analysis of TA showed that most examples displayed an X-chromosome inactivation pattern consistent with monoclonality. This monoclonal nature of TAs suggests that they display neoplastic rather than regenerative behavior; therefore, unlike regenerative lesions such as typical FNHs, they may present a risk of malignancy [1]. Diagnosis of a TA requires the observation of at least 4 of the following features: lack of a central scar, a heterogeneous lesion, hyperintensity in T1-weighted MR images, strong hyperintensity in T2-weighted MR images, and persistent contrast enhancement in delayed-phase contrastenhanced CT or T1-weighted MR images [7].

Benign hepatic tumors represent a broad spectrum of regenerative and true neoplastic processes. Many of these tumors present with characteristic features in imaging studies. The new classification of TAs has clinical relevance because they must be aggressively managed in the same way as HAs, whereas FNH may be managed by clinical follow-up alone.

\section{Abbreviations}

FNH: focal nodular hyperplasias; LCA: liver cell adenoma; TA: telangiectatic adenomas

\section{Consent}

Written informed consent was obtained from the patient for publication of this case report and any accompanying images. A copy of the written consent is available for review by the Editor-in-Chief of this journal.

\section{Competing interests}

The authors declare that they have no competing interests.

\section{Authors' contributions}

TCT conceived the study. RFC, FCC and RRB performed the literature review. TCT, AE, GZ and EM edit and coordinated the manuscript. All authors read and approved the final manuscript.

\section{References}

I. Paradis V, Benzekri A, Dargere D, Bieche I, Laurendeau I, Vilgrain V, et al: Telangiectatic focal nodular hyperplasia: a variant of hepatocellular adenoma. Gastroenterology 2004, I 26(5): 1323-9.

2. Bioulac-Sage P, Balabaud C, Bedossa P, Scoazec JY, Chiche L, Dhillon $\mathrm{AP}$, et al.: Pathological diagnosis of liver cell adenoma and focal nodular hyperplasia: Bordeaux update. J Hepatol 2007, 46(3):52I-7.

3. Hussain SM, Terkivatan T, Zondervan PE, Lanjouw E, de Rave S, ljzermans JN, et al:: Focal nodular hyperplasia: findings at state-ofthe-art MR imaging, US, CT, and pathologic analysis. Radiographics 2004, 24(I):3-17. discussion 8-9.

4. Choi BY, Nguyen MH: The diagnosis and management of benign hepatic tumors. J Clin Gastroenterol 2005, 39(5):40I-I 2.

5. Ferlicot S, Kobeiter H, Tran Van Nhieu J, Cherqui D, Dhumeaux D, Mathieu D, et al:: MRI of atypical focal nodular hyperplasia of the liver: radiology-pathology correlation. AJR Am J Roentgenol 2004, I82(5):|227-3|. 
6. Bioulac-Sage P, Rebouissou S, Sa Cunha A, Jeannot E, Lepreux S, Blanc $\mathrm{JF}$, et al:: Clinical, morphologic, and molecular features defining so-called telangiectatic focal nodular hyperplasias of the liver. Gastroenterology 2005, | 28(5): |2 | I-8.

7. Attal P, Vilgrain V, Brancatelli G, Paradis V, Terris B, Belghiti J, et al.: Telangiectatic focal nodular hyperplasia: US, CT, and MR imaging findings with histopathologic correlation in I 3 cases. Radiology 2003, 228(2):465-72.

8. Herman P, Pugliese V, Machado MA, Montagnini AL, Salem MZ, Bacchella $\mathrm{T}$, et al.: Hepatic adenoma and focal nodular hyperplasia: differential diagnosis and treatment. World J Surg 2000, 24(3):372-6.

9. Paradis V, Champault A, Ronot M, Deschamps L, Valla DC, Vidaud D, et al: Telangiectatic adenoma: an entity associated with increased body mass index and inflammation. Hepatology 2007, 46(I): I 40-6.

10. Zucman-Rossi J, Jeannot E, Nhieu JT, Scoazec JY, Guettier C, Rebouissou S, et al:: Genotype-phenotype correlation in hepatocellular adenoma: new classification and relationship with HCC. Hepatology 2006, 43(3):5I5-24.

II. Bioulac-Sage P, Rebouissou S, Thomas C, Blanc JF, Saric J, Sa Cunha $A$, et al.: Hepatocellular adenoma subtype classification using molecular markers and immunohistochemistry. Hepatology 2007, 46(3):740-8.

Publish with Bio Med Central and every scientist can read your work free of charge

"BioMed Central will be the most significant development for disseminating the results of biomedical research in our lifetime. "

Sir Paul Nurse, Cancer Research UK

Your research papers will be:

- available free of charge to the entire biomedical community

- peer reviewed and published immediately upon acceptance

- cited in PubMed and archived on PubMed Central

- yours - you keep the copyright 